GLOBAL JOURNAL OF PURE AND APPLIED SCIENCES VOL. 27, 2021: 181-192 COPYRIGHT@ BACHUDO SCIENCE CO. LTD PRINTED IN NIGERIA ISSN 1118-0579 www.globaljournalseries.com, Email: info@globaljournalseries.com

\title{
FIRST HORIZONTAL AND FIRST VERTICAL DERIVATIVES FROM HIGH RESOLUTION AEROMAGNETIC DATA OVER THE GONGOLA BASIN UPPER BENUE TROUGH NORTHEASTERN NIGERIA.
}

MUSA HAYATUDEEN, BELLO RASAQ, RAHEEM I. ONAOLAPO AND ABE, AYOOLA OLUMIDE.

(Received 16 March 2021; Revision Accepted 30 April 2021)

\begin{abstract}
High-resolution aeromagnetic data investigation was carried out over the Gongola basin upper Benue trough northeastern Nigeria. Total intensity magnetic map were processed to get the residual map, reduction to equator, polynomial fitting, radially average power spectrum (RAPS) were done, subsequently the first horizontal and first vertical derivatives of the data was carried out in order to identify linear structures (faults and fractures). The outcomes from both the horizontal and vertical derivatives give contact locations that are continuous, thin and show major structures in the NE-SW direction both in the maps and in the rose diagrams. The study focused on delineation of geological structures such as rock contacts; rock boundaries, fractures and faulted zones from the maps, they are principally important in mineral resources studies because many of these resources are located along fracture zones. Linear structures perceived in this kind of studies are also reliable indicators for geologic structures. The result of this work is also significant in identifying areas to be avoided when constructing bridges, dams as well as siting nuclear power plants and delineation of potential risk areas of natural hazard.
\end{abstract}

KEYWORDS: Aeromagnetic Data, first Horizontal Derivative, first Vertical Derivatives, Gongola Basin, Linear Features.

\section{INTRODUCTION}

The new high-resolution aeromagnetic data over the Gongola basin Figure1, for first horizontal and first vertical derivatives were handled exploiting the Oasis Montaj ${ }^{\mathrm{TM}}$ programming software to get the residual map by polynomial fitting and radially average power spectrum, thereafter the first horizontal and first vertical derivatives of the data were carried out in order to ascertain linear structures (faults and fractures). Situated between longitude $11^{\circ} 00^{\prime}-12^{\circ} 00^{\prime} \mathrm{E}$ and Latitude $10^{\circ} 00^{\prime}-11^{\circ} 00^{\prime} \mathrm{N}$, which is a portion of the Gongola trough a division of the upper Benue trough which is also a sub set of the Benue trough, a Cretaceous sedimentary basin, trending in N-S direction.
The Benue trough is generally said to have formed from a ridge- ridge-ridge structure which existed at the site of the present day Niger Delta in the early Cretaceous times, Kogbe, (1989), Ofoegbu, (1985), with arms as the Gulf of Guinea (R) the South Atlantic (R) and the Benue Arm $(R)$. The drainage feature of this region is characterized by the Gongola river which source is from the north central high lands poised of crystalline rocks. Important towns in the area are Gombe, Dukku, Akko, Kaltungo and Billiri.

\section{LITERATURE REVIEW}

On the evolution of the area, Abubakar, et al. (2010), discovered that there was mantle upwelling which resulted in crustal stretching and thinning, followed by a

Musa Hayatudeen, Department of Physics, Federal University of Kashere, Gombe state Nigeria.

Bello Rasaq, Department of Physics, Federal University of Kashere, Gombe state Nigeria.

Raheem I Onaolapo, Department of Physics, Federal University of Kashere, Gombe state Nigeria.

Abe, Ayoola Olumide, Department of Physics, Federal University of Kashere, Gombe state Nigeria. 
block faulting and lastly the emplacement of basic igneous material in the crust.

Studies by Bassey et al. (2017) on hydrocarbon viewpoint of Nigeria's Gongola basin based on gravity data understanding conclude that the basin may have essential physical condition for hydrocarbon generation/accumulation.

Analyzing the Gongola basin Zaborski et al. (1997) documented NE-SW trending lineaments that are accountable for the deformation and folding of the upper Cretaceous sediments.

Studies on lineament analysis from spot5 and Nigeria sat-X imagery, Ogumola et al. (2014), conclude that the upper Benue trough, Nigeria, is largely described by four major trends NE-SW, NW-SE, E-W and N-S in order of abundance.
Studies by Fitton (1980), on the migrating rift system in West Africa shows that the Benue trough and the Cameroun volcanic line have semblance in shape and that they are linked to a common " $Y$ " shaped hot region in the asthenosphere over which the African plate has progressed.

Analysis on an organic geochemical perception on a migrated oil controversy on the petroleum prospectivity of Cretaceous formations in the Gongola basin, upper Benue trough, Nigeria, Abubakar, et al. (2008), propose that the manifestation of the migrated oil in the Bima formation and its probable lacustrine source propose that the petroleum system in the Gongola basin is comparable to that of the Termit, Doba and Doseo basins of the Chad Republic, where commercial oil reserves have been encountered.

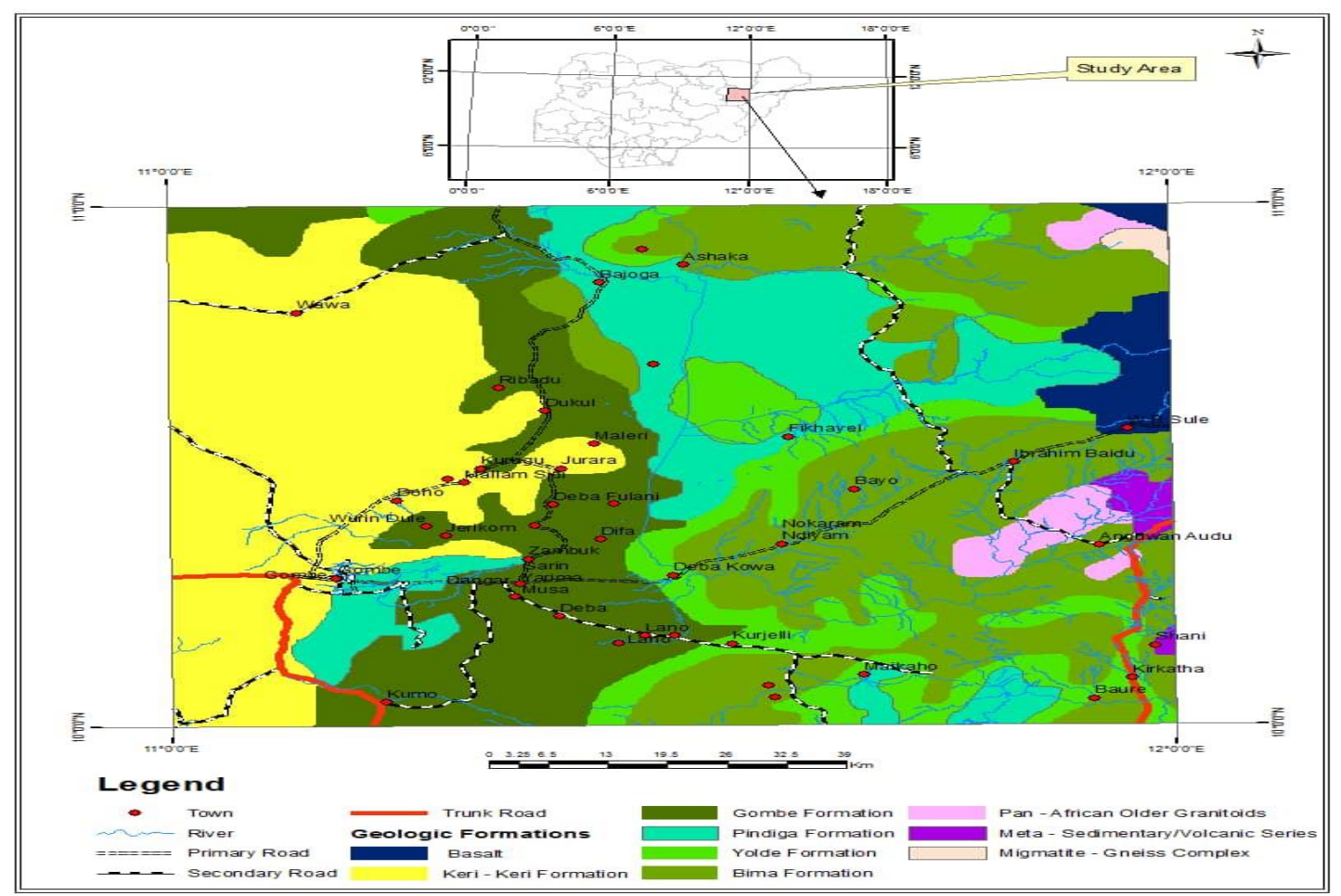

Figure1. Geologic map of the study area.

\section{GEOLOGY OF THE STUDY AREA}

The study area lies in North East Nigeria between longitude $11^{\circ} 00^{\prime}-12^{\circ} 00^{\prime} \mathrm{E}$ and latitude $10^{\circ} 00^{\prime}-11^{\circ}$ $00^{\prime} \mathrm{N}$. It is situated within the Gongola basin which is the western sector of the upper Benue trough, a N-S trending structure and a sub set of the Benue trough. Naturally the basin is an intracontinental linear shape sedimentary basin that runs from the south to the north east of Nigeria, which is well over $1000 \mathrm{~km}$ long and $100-700 \mathrm{~km}$ wide. Its shape proposes a linear structural control on its formation of which numerous models base on rift origin were suggested. Some authors have put forward divergent models for the origin and evolution of the Benue trough in the context of plate tectonic concept. Several authors considered it as an Aulacogen and part of a three arm rift system involving the South Atlantic Ocean, others consider it to be a true rift and compared it to the Afar region of north east Africa.

\section{MATERIALS AND METHODS}

The high-resolution aeromagnetic data used for this investigation was made available by Nigeria Geological Survey Agency (N.G.S.A) and was acquired in 2010 by Fugro international of Netherlands for N.G.S.A. It encompasses four sheets 131,132, 152 and 153 which were fused together to form a composite sheet. Efforts has been made to use several software's for example Winglinks, surfer 7 and 8 to process the data but the data appears too heavy for them, hence the need for a bigger software such as the Oasis Montaj. Ever since aeromagnetic data are presented as maps, in this study, the presentation formats take account of coloured fill maps, contour maps and rose diagrams. Different presentation formats expedite the assessment and identification of different feature of interest. The interpreters' mission is to detect anomalies enclosed within the maps and qualitatively or quantitatively 
understand and infer them into geologic structures at depth. This ensures that the facts contained in the transforms can be employed in the interpretation segment, according to Peterson and Reeves (1985), color map format facilitates the assessment of regional inclinations and magnitude discrepancy. A variety of filtering technique was employed so as to improve the data set used in this study. The final choice of processing data hinges on which aspect of the anomalies one aim to enhance. The tenacity of filtering a data set is to eliminate certain unwanted characteristics and to enhance desired characteristics that are diagnostic of the geology. The principal objectives of filtering aeromagnetic data are to condition the data set and to render the result presentable in such a way as to make it easier for the geoscientist to comprehend and interpret the significance of anomalies in terms of their geologic cause and settings. Using filters in data interpretation constantly enhance the data and help express features that were tough to detect before filters, selected filters utilized in this research are:

REDUCTION TO EQUATOR Aeromagnetic figures at low magnetic latitude such as those of the region are challenging to interpret because magnetic anomalies remain displaced from their causative sources, Grauch et al. (2004). Pole reduction is difficult at low magnetic latitudes since some bodies have no detectable magnetic anomaly at zero magnetic inclination, Grauch et al. (2004). Also reduction to pole of such data introduces N-S alignment of anomalies into the data there by making the data unusable. In such cases reduction to equator can be realized. Reduction to equator makes all vertical components in a field horizontal using Fourier transformation which removes inclination effect from the data so that the resulting magnetic field appears as if the magnetic effect of the body in question is calculated at the equator. Also it is effective in eliminating the effect of a strong remnant component and significantly improves the correspondence of anomaly pattern to known geology. Differential reduction of magnetic anomaly to the equator on a massively parallel computer will allow each anomaly to have different inclination and declination and thus greater accuracy, Lu et al. (2003).

Assume that we have a set of observed magnetic data acquired on a planar observation surface. Let $A e(u, e)$ be the Fourier transform of these observed magnetic data. Ap $(u, u)$ be the Fourier transform of the vertical magnetic field that would be perceived at the same positions when the magnetization is similarly vertical (the RTP field), at that point the RTP operation in wave number domain can be said to be ;

$$
A_{p} \quad(u, v) \quad=\frac{A e(n, v)}{(\sin I+i \cos I \cos (D-\theta)) 2}
$$$$
1
$$

Where $I$ and $D$ is the inclination and declination of main field. $(u, v)$ is the wave number analogous to the $(x, y)$ directions separately, $\theta$ arctan $(u / v)$ and $i^{2}$. Now the condition of horizontally magnetization. i.e. I 0 , and $D, \theta$ is close $\pm 90^{\circ}$, which brands the imaginary part close to zero, the RTP operator to be unrestrained. Consequently, the RTP dispensation will be unstable at low latitudes and singular at the equator. To overcome this difficulty, bearing in mind another form of Eq. (1
$A e(u, v) A_{p}(u, v) \quad\left(\sin I+i \cos I \sin (D \quad \theta)^{2}\right.$. 2

This is the stable operation named special reduction to equator. At this point the operation is different from the traditional sense not commonly referring to the magnetization direction transform to the equator. It is a distinct operation to transform vertical magnetic field that will be perceived at the same position when the magnetization is also vertical (the RTP field) to the observed magnetic data near or at the geomagnetic equator. It is the inverse manner of reduction to pole or at low latitudes or at the equator, fundamentally, Luo et al. (2010). The filter of superior reduction to the equator in wave number domain can be expressed as:

3

$$
[\sin 1+i \cos \mid \sin (D-\theta)]^{2}
$$

The magnetic data was reduced to the equator (RTE) such that the magnetic figures will seem horizontal next to the equator Leu, (1982). The structure will display the same anomaly shape as those by the poles. His methodology recalculates the total magnetic body supposing the magnetic body is lying in a horizontal position and anomaly lows are altered to magnetic highs by reversing the phase by 180 at the same position over the middle of the bodies. From model studies, Jain (1988) displayed that while the magnetic field is further multifaceted next to the equator than the real magnetic field next to the pole, a reduction to equator map is less difficult.

Upward Continuation This is the projection of potential field data higher than the level at which the field was measured. This method is employed in magnetic interpretation to determine the form of regional magnetic variation over a survey area. A potential field measured on a given observation plane at a constant height can be calculated as though the observation were made on a different plane, higher (upward). This involves the application of Green's Theorem and it is unique if the field is completely known over the lower surface. Upward continuation is generally a useful and physically meaningful filtering operation. It allows one to smooth the field and eliminate small anomalies from near surface objects. Thus producing a map in which more regional features predominate. Upward continuation is derived from relatively deep structures and consequently represents a valid regional field for the area. The method is useful in the interpretation of magnetic anomalies over areas containing many near-surface magnetic sources such as dykes and other intrusions, Keary et al. (2002).

The equation of upward continuation is given by Telford et al. (1990) as;

$\mathrm{F}(\mathrm{x}, \mathrm{y},-\mathrm{h})=\frac{\mathrm{h}}{2 \pi} \iint \frac{\mathrm{f}(\mathrm{x}, \mathrm{y}, 0) \mathrm{dxdy}}{\left\{\left(\mathrm{x}-\mathrm{x}^{\prime}\right)^{2}+\left(\mathrm{y}-\mathrm{y}^{\prime}\right)^{2}+\mathrm{h}^{2}\right\}^{1 / 2}}$

4

where $f\left(x^{\prime}, y^{\prime},-h\right)=$ is total field at point $\left(x^{\prime}, y^{\prime},-h\right)$ above the surface on which $f\left(x^{\prime}, y^{\prime},-0\right)$ is know.

$\mathrm{H}=$ continuation height.

This function declines progressively with increasing wave number, weakening the higher wave number anomalies associated with such features and enhances, relatively, the anomalies of the deeper seated sources. 
Radially Averaged Power Spectrum A potential field may be considered as representing a series of interfering waves of different wave length and direction. The power of each wave length can be plotted against wave number regardless of direction, to produce a power spectrum. In the frequency domain, one can prepare and analyze the distribution of short to long wave length across all measured high to low frequency. The radially average power spectrum can be broken into sequences of straight line segments, each section signify the collective response of an ensemble of sources at a given depth. The depth is directly proportionate to the slope of the line section. The slope of each segment provides information about the depth to the top of an ensemble of magnetic bodies, Kivior and Boyd (1998). The slope (M) of the best fitting straight line to the semi log plot of power vs. wave number is = $2 z$. If however, the frequency unit is in cycles per kilometer, the corresponding relation can be expressed as $-4 \pi z$ where $z$ is the mean depth of ensembles. Therefore $z=-M / 2$ or $-\mathrm{M} / 4 \pi$ 5.

The study area was divided into 16 Blocks $(30 \mathrm{~km} \times 30$ $\mathrm{km})$ fig. 5 to get the depth to magnetic sources.

First Horizontal and First Vertical Derivatives the final filtering techniques employed in this study are the first horizontal and first vertical derivatives. These and other filters are the most frequently used for preparation of final potential data product, Blackly (1998). Also Nelson (1998), Christensen and Dransfield (2002), stated that the first horizontal derivatives remain magnetic vector filter that provides additional information about the directional variations of the whole magnetic field. Horizontal derivative maps are a derivative product which expose the anomaly texture and emphasizes anomaly pattern discontinuities. According to Hogg (2004), first horizontal derivatives can deliver advanced resolution and bigger accuracy at wider line spacing. It is potentially significant while trying to map out linear structures such as faults or dykes from magnetic data. The horizontal derivative of an anomaly field is considered as the Pythagorean sum of the gradient in orthogonal direction. If $\mathrm{M}(\mathrm{x}, \mathrm{y})$ is the magnetic field, then the horizontal derivative:

HGM $(x, y) \quad=\quad \sqrt{\left(\frac{d m}{d x}\right)^{2}+\left(\frac{d m}{d y}\right)^{2}}$

6

This task peaks over magnetic contacts on the postulation that the local magnetic field and source magnetization are vertical, that the regional magnetic field, the source magnetization, the contacts are vertical, isolated and the source are thick Philips (2000).
According to Fairhead (2007), the ridges or maxima of the horizontal derivatives are acknowledged by the industry generally as being worthy locators of shallow, vertical edge bodies. This filtering technique is considered as the simplest method to estimate the contact location (e.g. faults), because the gradients is largest at edges of horizontal bodies. It entails a number of assumptions about the source. While first vertical derivatives improve the lineament and anomaly owed to their short wavelength character, they also resolve or sharpen anomalies of minor areal magnitude, they improve shallow sources at the expense of deeper sources as stated by Fairhead (2007), the edges of anomalies become sharper or stronger if derivative operators are applied to the data. Vertical derivatives emphasize short wavelength component of anomaly field, while de-emphasizing long wavelength component. The first vertical derivative is a very good technique for determining anomalies over distinct structures in total magnetic intensity data and remarkably suppresses the regional content of the data. As stated by Fairhead (2007), vertical derivatives cannot be considered in the space domain as in the case of the horizontal derivatives since it requires facts on how the field diverges and declines with height and this can only be determined by investigating the radially average power spectral of the data. This can be reflected in the rate of recurrence domain and can be reproduced using the fast Fourier transform (change) or from the space domain using Laplace's equation.

Thus:

$\frac{d^{2} T}{d x^{2}}+\frac{d^{2} T}{d y^{2}}+\frac{d^{2} T}{d z^{2}}=0$

\section{Results and Discussion}

\section{4a. Results}

The magnetic intensity map of the study area (TMI), figure 2, illustrates the anomalies of high and low magnetic intensity values of 226 to $-107.6 \mathrm{nT}$ with prevailing NE-SW trends. The prevailing long wavelength anomalies with spatial scales of several kilometers are undoubtedly due to deep seated basement under the basin. The map illustrates that the area is composed of different magnetic region. The regions are distinguished on the source of the difference of the strength of magnetic response. The north-eastern side is categorized by low magnetic anomalies, while the central part is categorized by highs. In this research, data was residualized (i.e. removal of the regional) leaving only the residual so as to obtain a magnetic response from the upper-crust of the earth 
encompassing of the basement and sedimentary unit. The residual anomaly map showed in figure 3 displays magnetic anomalies similar to the TMI map in figure 2. The anomalies of 260.9 to $-95.7 \mathrm{nT}$ exist as a sequence of areas of magnetic highs and lows. The principal trend is in the NE-SW direction, which is related to the Pan
Africa trend. The long wavelength features are undoubtedly due to very deep basement source and are referred to as regional. Small amplitude short wavelengths anomalies are superimposed on these large

features.

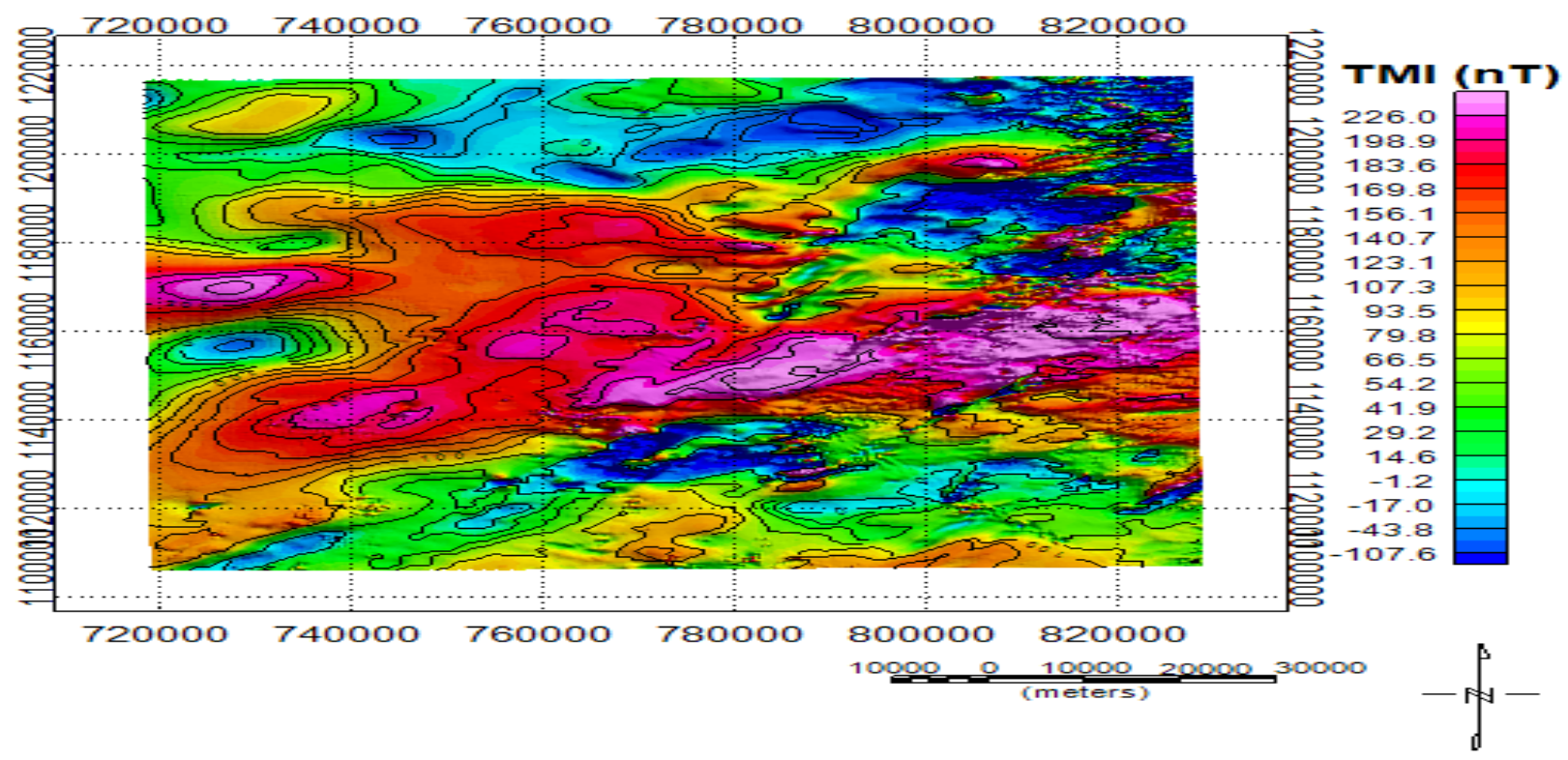

Figure 2: Total magnetic intensity map of the study area.

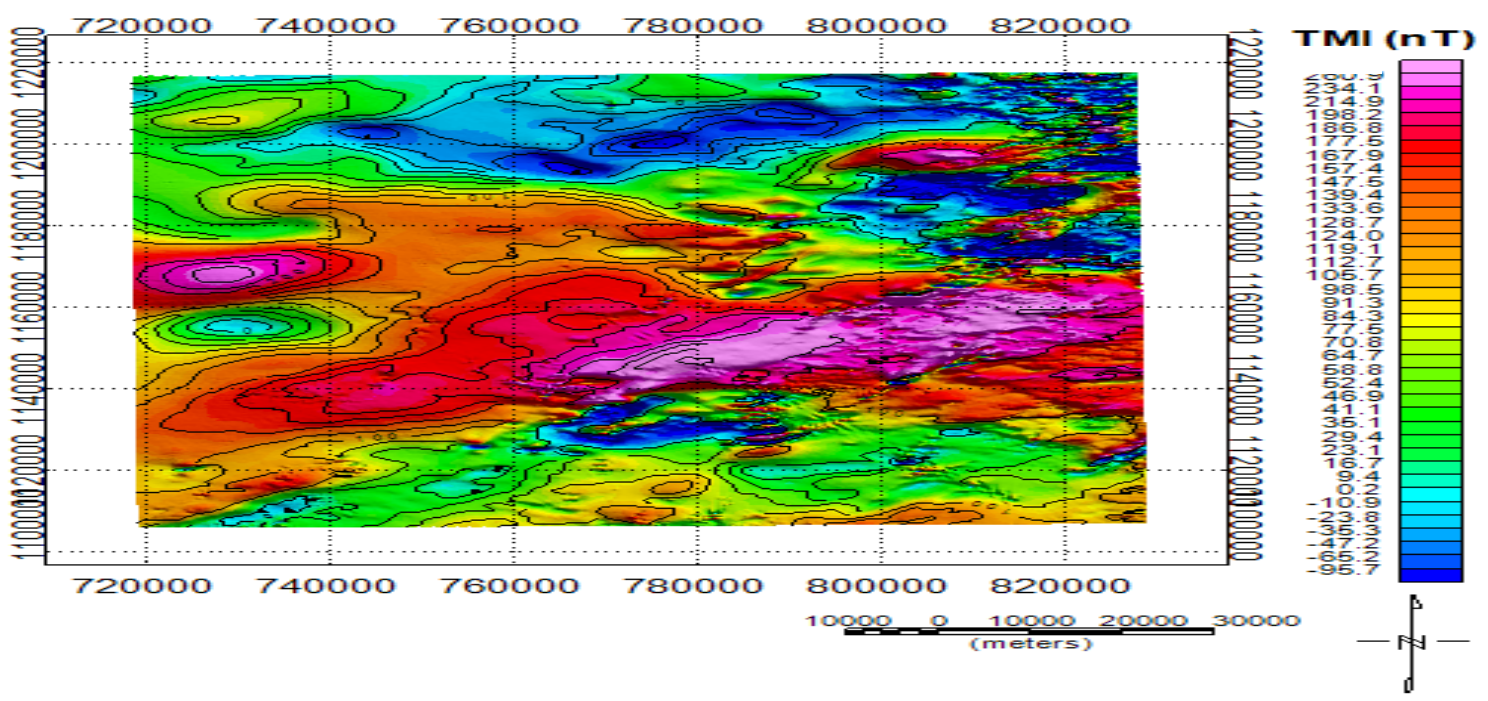

Figure 3. Residual map of the study area. 
Reduction to equator transformation corrects for offsets between the locations of anomalies and their source that is consequence of inclination of earth field at a given location. For the vital resolve of precise positioning of the anomalies, the aeromagnetic data remained initially reduced to the equator prior to further processing and analysis. This filter displays that the magnetic anomalies are slightly shifted northwards by this process figure 4 , comparism of the reduced to equator map with that of total magnetic intensity map displays a northward shift in locating the anomalies by $2 \mathrm{~km}$, the implication is that any geologic structure mapped in the area on the basis of total magnetic strength might be mislocated by $2 \mathrm{~km}$, if the data is not reduced to equator.
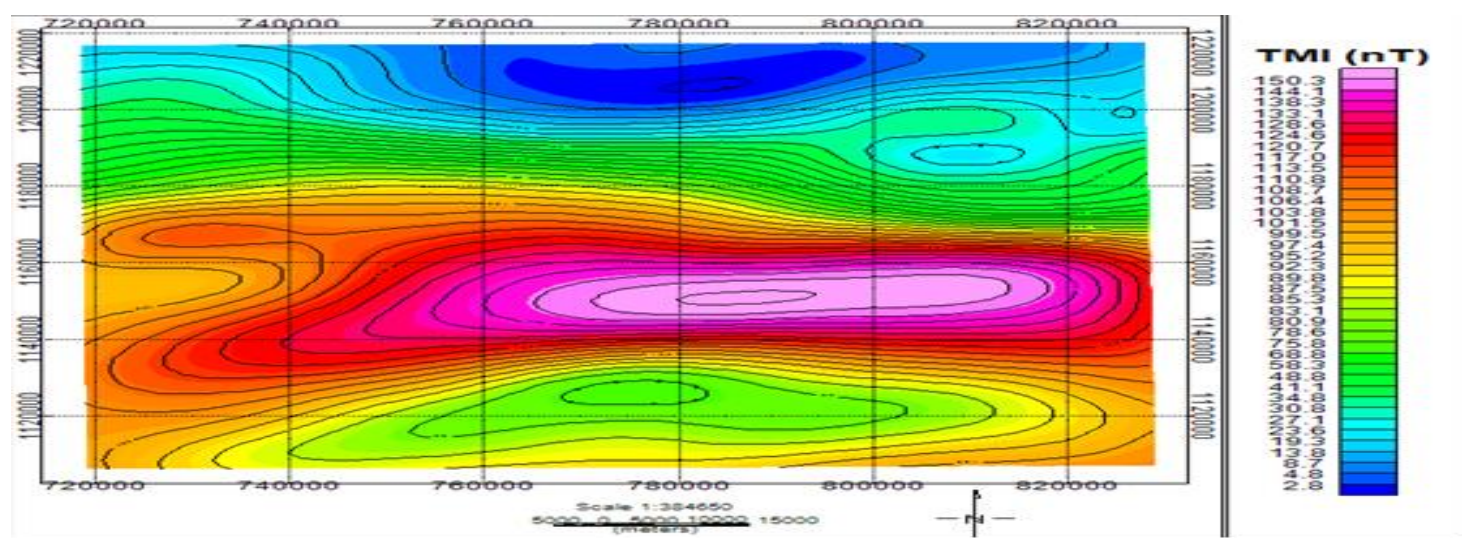

Figure 4. Reduced to equator map of the study area.

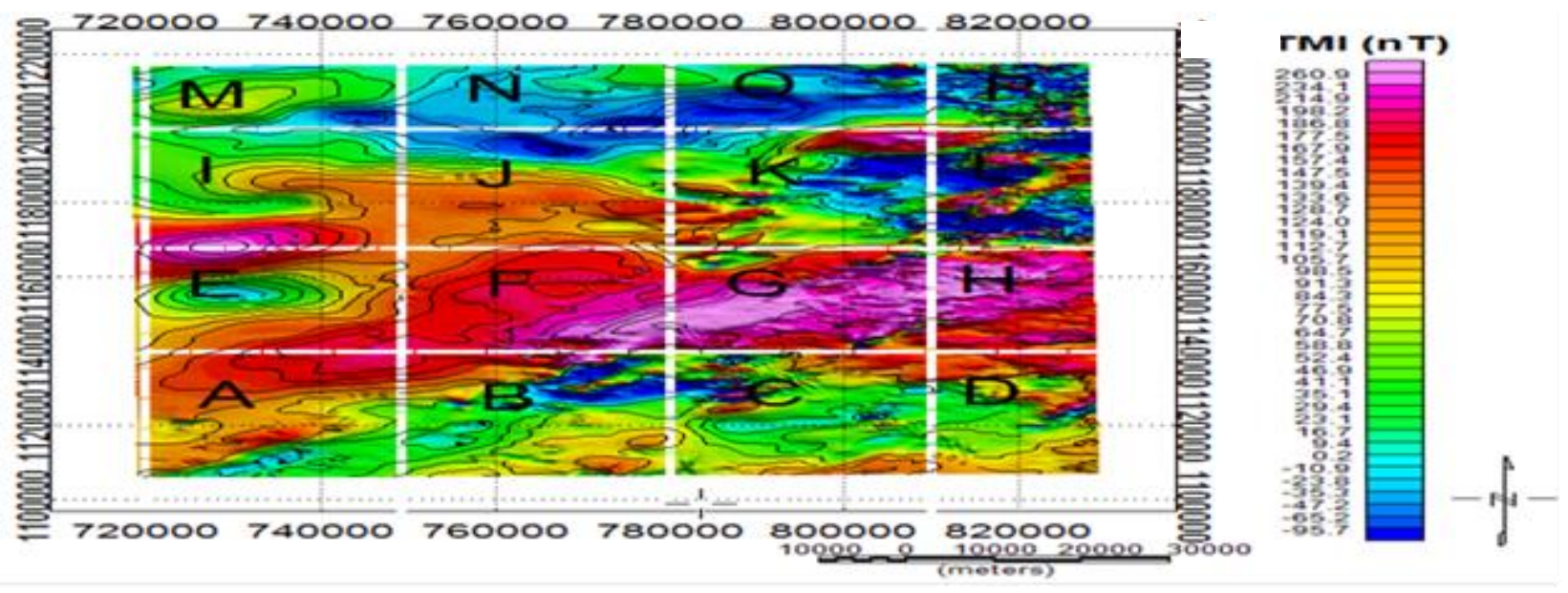

Fig. 5. Residual map showing the 16 Blocks ( $30 \mathrm{~km} \times 30 \mathrm{~km}$ ) used in computing the spectral depth.

Spectral analysis was accepted to regulate the depth to basement and basement topography, as stated earlier by Fairhead (2007), vertical derivatives cannot be considered in the space domain like in the case of the horizontal derivatives since it requires facts on how the field diverges and declines with height and this can only be determined by investigating the spectral content of the data, the spectral analysis is characterized by 2 and 3 energy spectrum, block $\mathrm{G}, \mathrm{I}, \mathrm{J}, \mathrm{K}, \mathrm{L}$ and $\mathrm{N}$ have 3 energy spectra while the rest have 2 , figure $6(A-P)$. The result of the spectral analysis shows the presence of shallow source bodies ranging from $0.5-1.5 \mathrm{~km}$ for shallow sources these could be due to near surface or shallow basement, while the deeper sources are in the range of 1.2 to $5 \mathrm{~km}$ signifying the depth to deep seated basement. The essence of this enhancement is to define the depth of volcanic intrusions, depth to basement and subsurface geologic structures. The power spectral of the total strength magnetic field, as indicated by Oladele et al (2008) shows the dispersion of short to long wave 
number over-all series of interfering magnetic responses of contrasting wave number and direction. This result is in covenant with the outcome of numerous workers such as, Salako (2014) who studied the northern sector of the Benue trough and some section of Borno Basin, N.E. Nigeria exploiting source parameter imaging and acquired sediment thickness of 5.0 kilometers in the region. Studies on the Gongola trough a division of the upper Benue trough Bassey et al. (2017) posits that the sediment thickness (depth to basement) in the region from spectral analysis of gravity data is in excess of 4 $\mathrm{km}$, the outcome of the spectral analysis for this investigation is here presented in figure 6 (A-P).

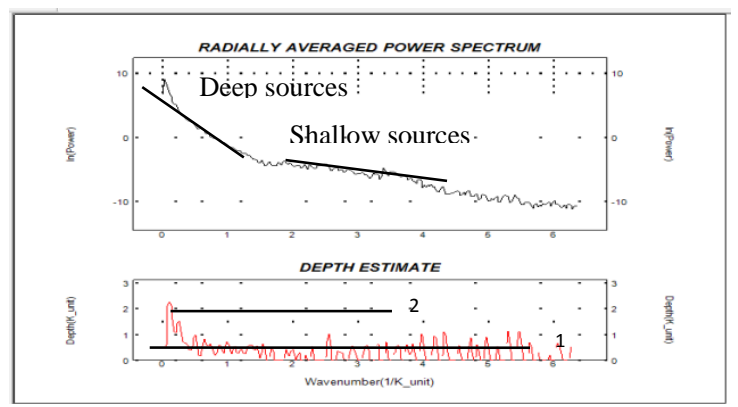

A

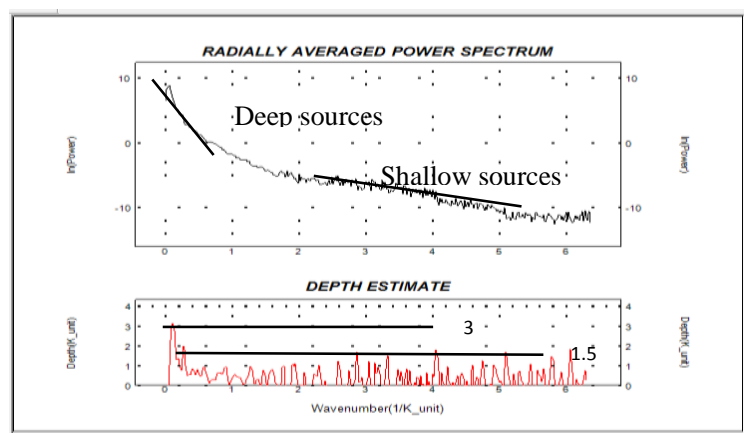

C

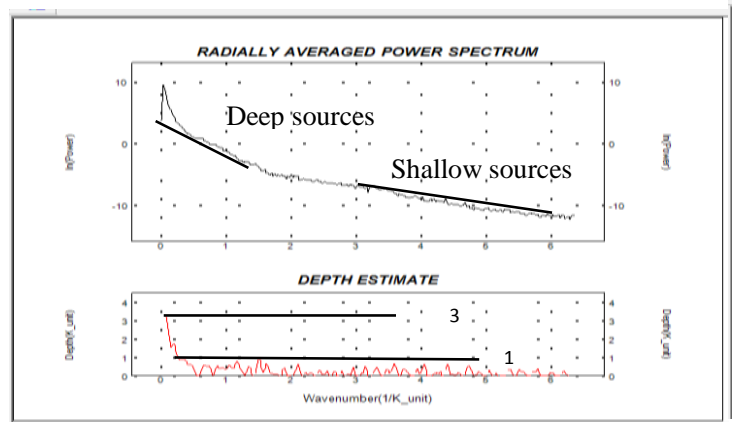

$\mathrm{E}$

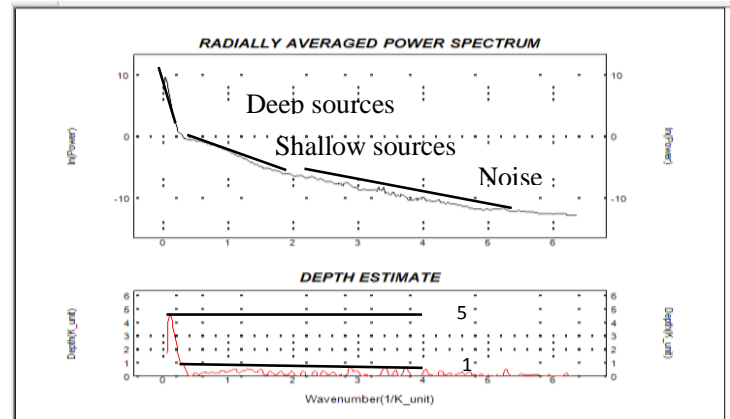

G

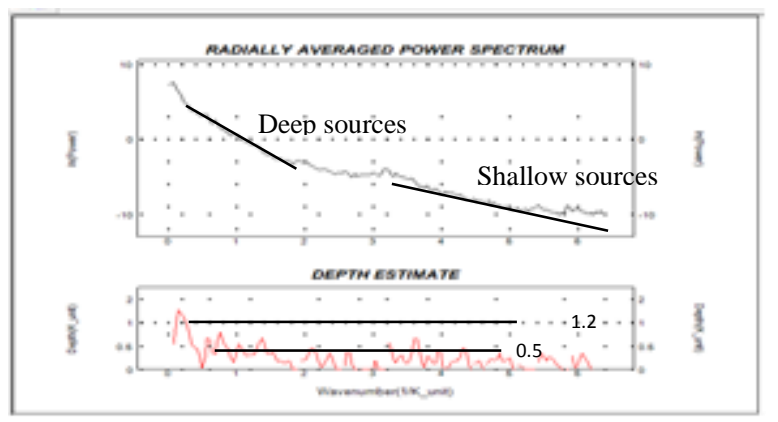

B

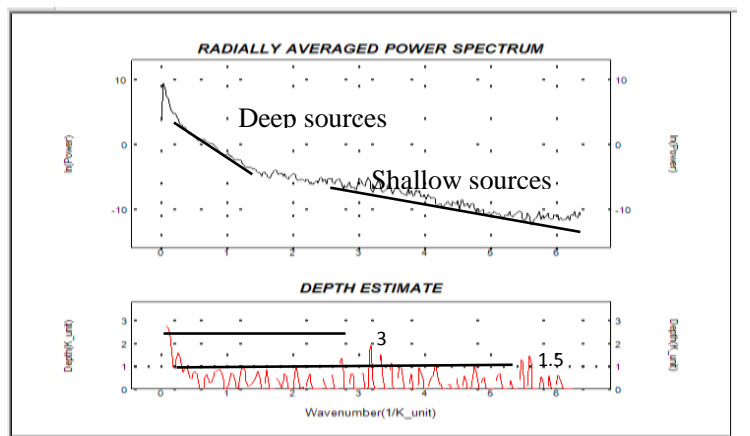

D

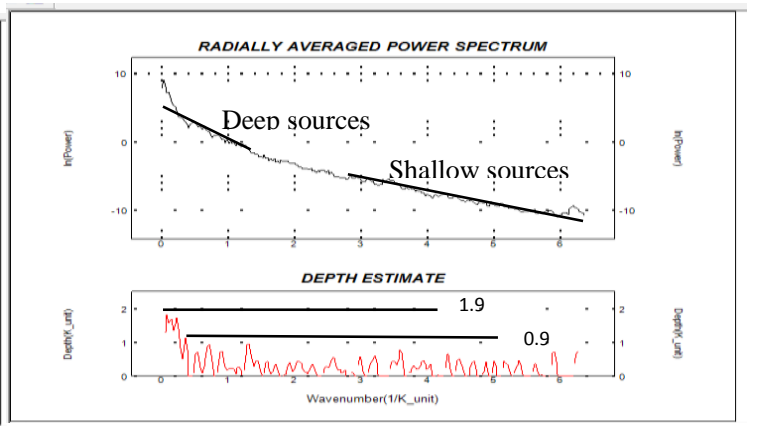

F

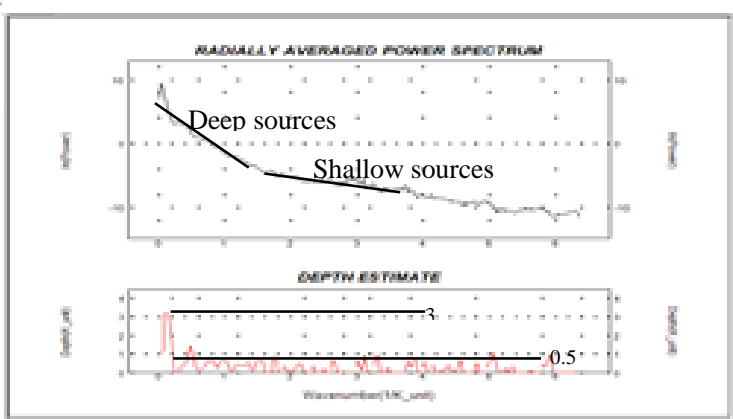

$\mathrm{H}$ 

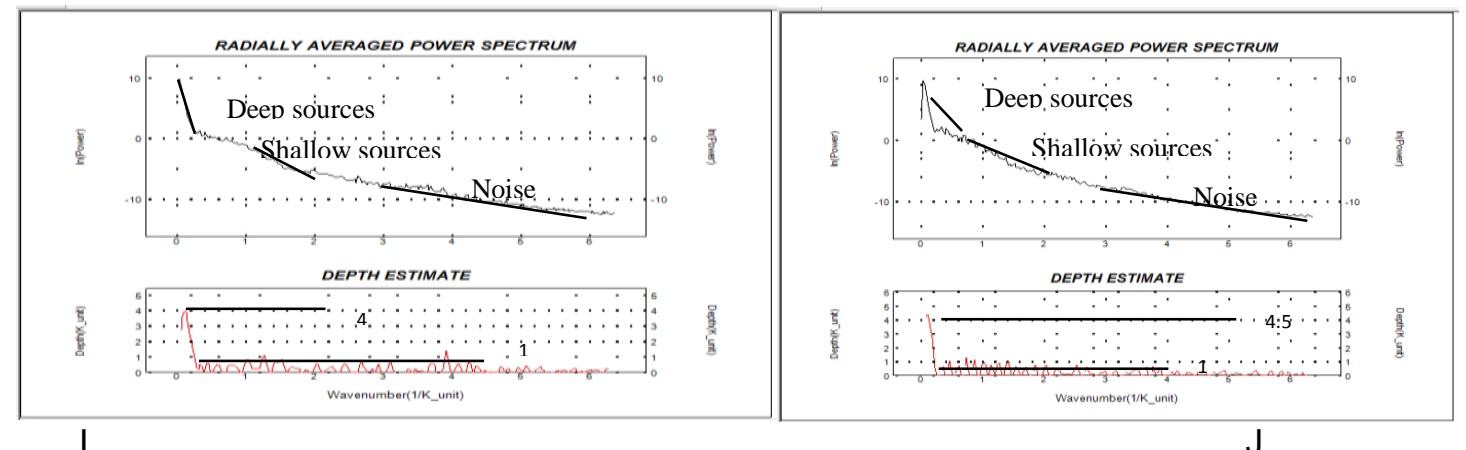

I
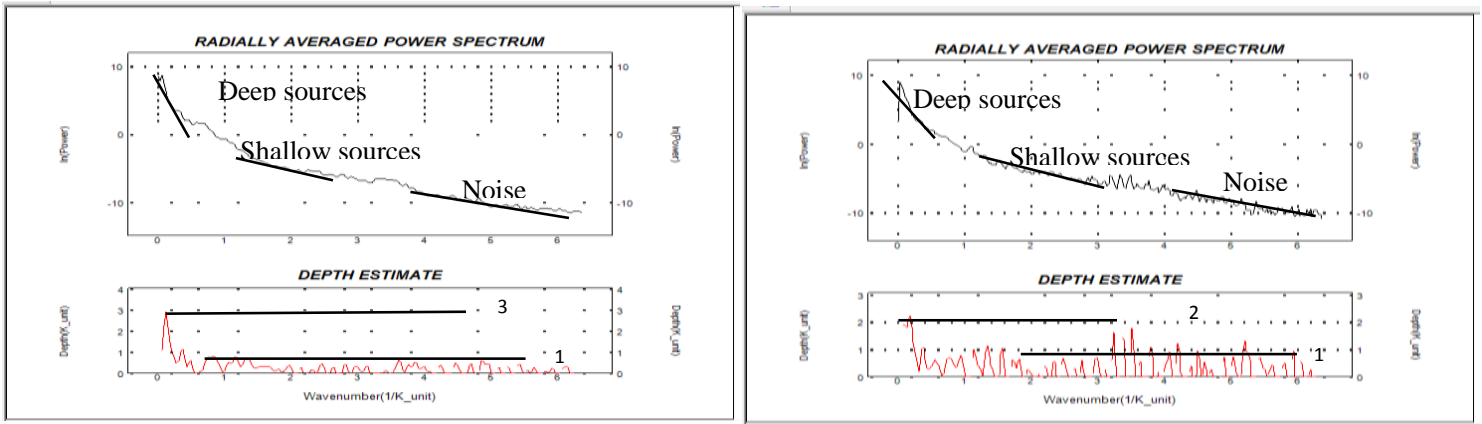

$\mathrm{K}$

L

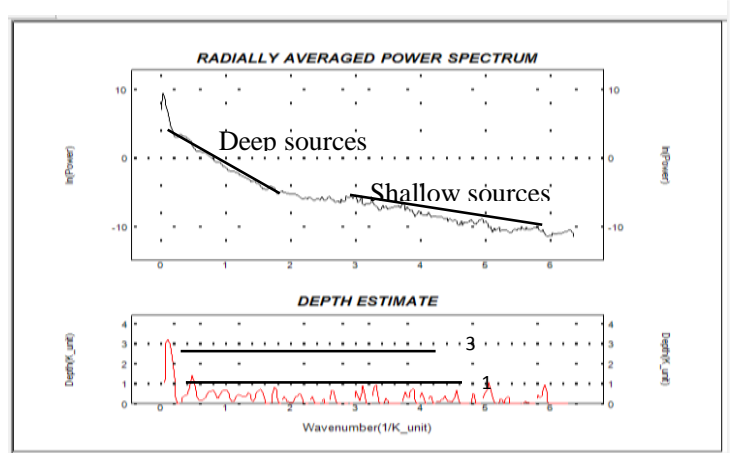

$\mathrm{M}$
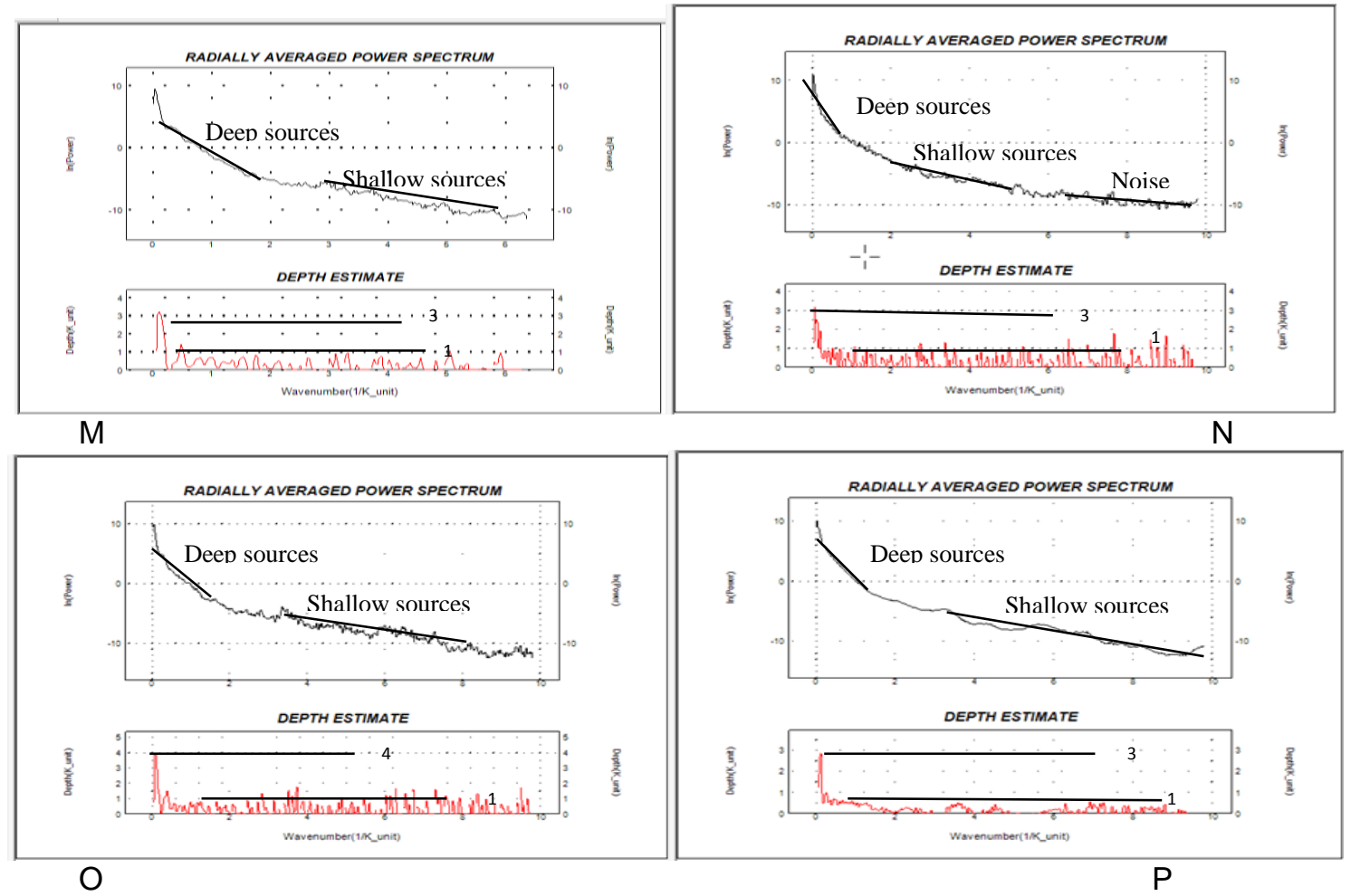

Figure $6(A-P)$ result of the spectral analysis of the study area. 


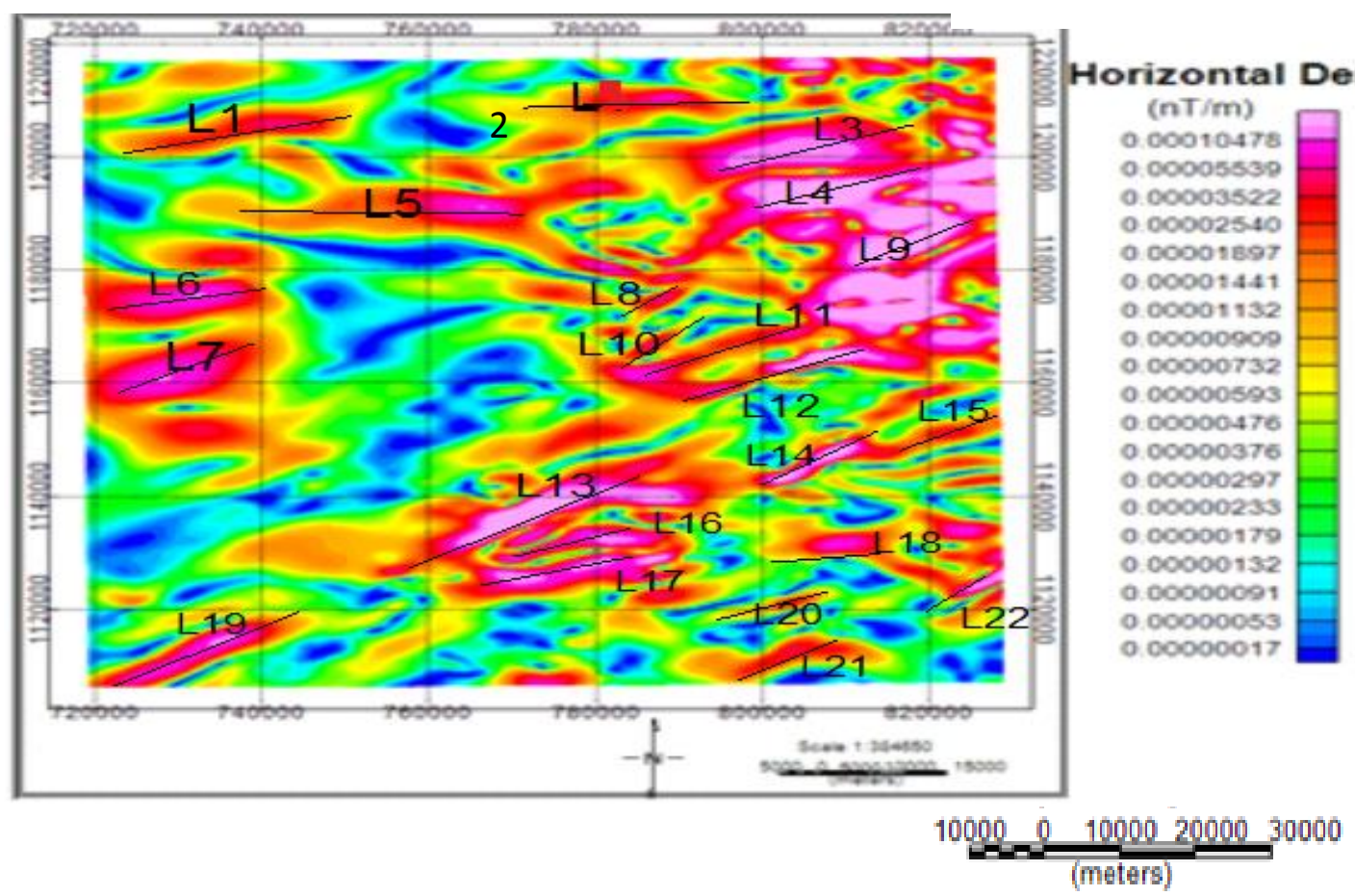

Figure 7. Horizontal derivative map of the study area.

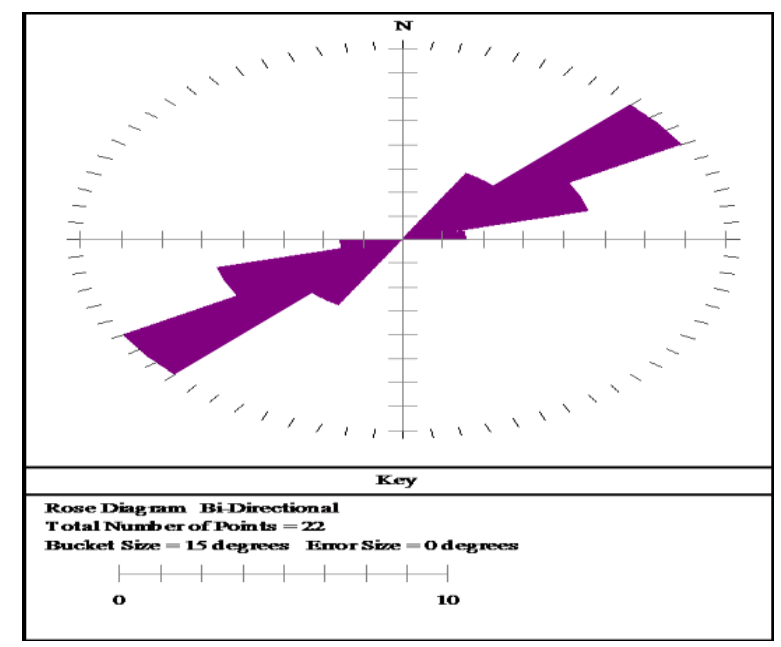

Figure 8. Rose diagram of the horizontal derivatives map of the study area.
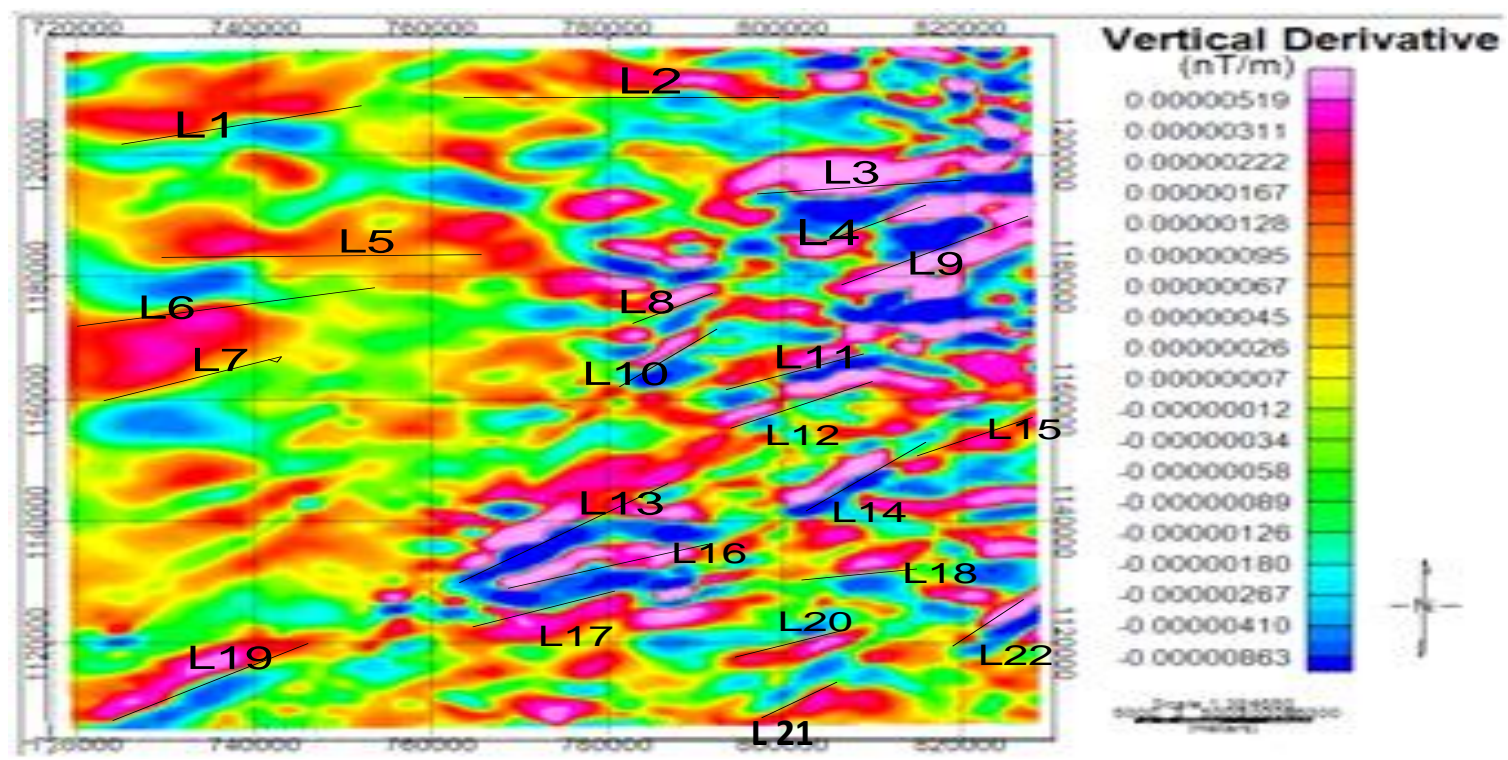
Figure 9. Vertical derivatves map of the study area.

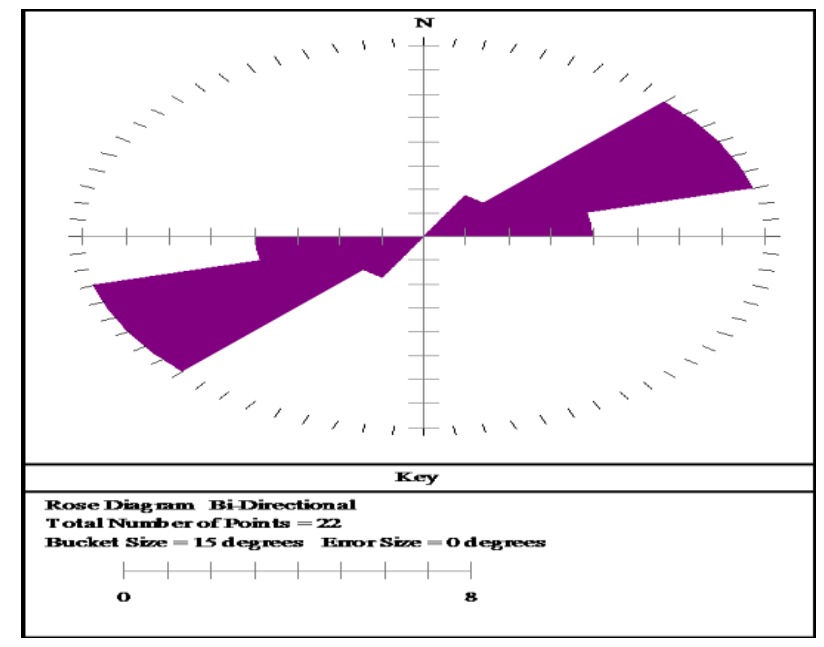

Figure 10. Rose diagram of the vertical derivatves map of the study area.

\section{DISCUSSION}

The reduced to equator map of the region displays a northward shift in position of the anomalies by $2 \mathrm{~km}$, this will be implcative to the structures mapped in the region if the data is not reduced to equator. The end product of the spectral analysis is in conformity with what was obtained by earlier workers in the region such as Bassey et al (2017) and Salako (2014). The power spectral analysis will give the idea where this structures will be encountered, the shallow sources may be found in the sedimentary secton while the deeper sources are deep regional structures. The horizontal derivative map demonstrates anomalies of high and low values with dominant NE-SW trend. The dominant long wavelength components with spatial scales of several kilometers are undoubtedly due to deep basement under the basin. The linear structures which frequently present contrasting magnetic signatures that fluctuate significantly from that of the rocks that host them (may be due to recrystallization of existing rock minerals across the fracture or due to infilling of fracture with younger material) were extracted to express the structural framework of the study area. The horizontal derivatives results give contact locations that are continuous and thin and display major structures in the NE-SW direction both in the map and in the rose diagram (figures 7 and 8), it can be used comprehensively to map out the margins of susceptibility differences. It exploits the detail that the horizontal derivative of the magnetic field caused by a tabular body tends to have maximum values in excess of the boundaries of the anomalous body in case the edges are vertical and well-separated from each other, it is not only less subtle to the noise in the data, but also robust in exposing shallow magnetic sources. It has high amplitude over the edge of the magnetic source. Whereas the vertical derivative was first applied to outline edges of magnetic bodies. It is usually applied to the data to focus near-surface geological features and further improve the high wavenumber constituents of the spectrum where the zero values of vertical derivatives of the magnetic field generally correspond to the geological boundaries. It is also applied to the data to further enhance the most shallow geological source. The enhancement improves anomalies over features and inclines to decrease anomaly complexity, permitting a perfect imaging of a causing structure. The vertical derivative also expresses major structures in the NE-SW direction both in the map and in the rose diagram as shown in (figures 9 and 10). Vertical derivative data have become virtually a basic necessity in magnetic data interpretation projects. Deformational features such as joints, faults, folds are frequently credited to an unexpected discontinuity of the magnetic unit, offsets of seemingly analogous magnetic units, and sudden adjustment in depth to magnetic sources, magnetic anomalies shape as well as geometry of magnetic sources, Philips (2000) these geologic features are expressed as linear narrow magnetic low anomalies (associated with weathering) within magnetic highs or otherwise using regulated magnetic gradients, Fairhead (2007). The structural trends of the region resemble faults, geologic boundaries, folds and tectonically associated structures that is producing the ruggedness of the basement topography. Patterns of the linear amplitude of anomalies on both the horizontal and vertical derivatives maps display noticeable NE-SW trend which is credited to Pan African orogenic cycle of deformation. This agrees with Ofoegbu and Morhan (1990) that there are major NE-SW and NW-SE trending lineaments in the Benue trough, also Benkhelil (1986), testified the existence of NE-SW faults which are major faults following the major trend of the Benue trough. This research is ideal for developing countries as reconnaissance type studies, vast areas in Nigeria has not been mapped and there are scanty information about those areas, study area inclusive, therefore the importance of these type of studies can be a valuable tool in revealing their potentials geologically. Among the cheap, inexpensive ways of locating natural resources in developing country like ours is by the use of reconnaissance studies. Because large areas are involved, and the system appear to be promising for geologic exploration, Verduco et al (2004), Isorho (1984). Linear structures observed in this kind of studies 
are reliable indicators for geologic structures, they are particularly vital in mineral resources exploration programmes because many of these resources are situated along fracture zones Curan et al. (1982). Since these resources are often related with faults, fault intersections and such regional features, linear structural analysis will consequently, facilitate for planning, preparation and exploration of these resuorces. The siting of these structures will aid in mineral resources exploration which will be essential for any developing nation like Nigeria. Government at all levels should as a matter of urgency mandate its relevant agencies to carry out detail survey of both regional and local structures most especially regionally deep seated faults and local fault in-tersections that are deeply inclined, these can conduct ore bearing fluids from deep to shallow sites. Many regional and local fault structures can be traced from the basement rocks onto the adjacent sedimentary rocks. Detailed structural and geologic studies of these areas should be carried out for possible mineralization, Bello et al. (2020). The end result of this work can also be utilized in recognizing areas to be avoided when constructing bridges and dams so also for siting nuclear power plants.

\section{CONCLUSION}

This reseach was perfomed to delineate linear structures from first horizontal and vertical derivatives enhancement technique of the high resolution aeromagnetic data and the spectral analysis was perfomed to determined the origin of these structures. The horizontal derivatives results give contact locations that are continuous and thin, it can be used comprehensively to map out the boundaries of susceptibility contrasts. While the vertical derivatives delineate edges of magnetic bodies, and near-surface geological features, it is also used in detecting shallow geological source. The horizontal and vertical derivatives maps show prominent NE-SW trend which is attributable to Pan African orogenic cycle of deformation. An important aspect of this research is that it will aid in the identification of structural and lithologic information more efficiently and cost effectively and can be a valuable tool in revealing their potentials geologically. The end product of this work will also be used in identifying areas to be avoided when constructing bridges and dams as well as siting nuclear power plants and delineation of potential risk areas of natural hazard.

\section{REFERENCE}

Abubakar, MB; Dike, EFC; Obaje, NG; Wehner, H; and Jauro, A. 2008. Petroleum Prospectivity of Cretaceous formations in the Gongola basin, upper Benue trough, Nigeria: An organic geochemical perspective on a migrated oil controversy. Journal of Petroleum. and Geology.

Abubakar, YI; Umegu, MN; Ojo, SB., 2010. Evolution of Gongola Basin, upper Benue trough N.E Nigeria. Asian Journal of Earth Sciences 1:62 67.
Bassey, NE, Jonathan, B, Musa, H, and Abubakar, T., 2017. Hydrocarbon prospect of Nigeria's Gongola basin based on gravity data interpretation. Journal of Applied Geology and Geophysics 5(2): 68-77.

Blackely, RJ., 1998. Potential theory in Gravity and magnetic applications, Cambridge University press. 313 .

Bello R, Hayatudeen M, Bassey NE and Kaigama U., 2020. Depth Estimation, Structural Features and Mineralization from High Resolution Aeromagnetic and Satellite Data over Yola Arm of the Upper Benue and Adjoining Basement Regions, Northeastern Nigeria. Petroleum and Coal; 62(4) 1163-1171.

Benkhelil, JM., 1986. Structural and geodynamic evolution of the intracontinental Benue Trough (Nigeria) Elf Nigeria Itd SNEA(P). 97-169.

Christensen, A and Dransfield, M., 2002. Airborne vector magnetometry over banded iron formations, 72nd Annual International Meeting, Society of Exploration Geophysics. 13-16.

Curan, SC; Woodruff, CM Jr; Thompson, EJ., 1982. Lineament analysis and inference on geologic structures - examples, from the Balcons / Ouchita trend of Texas. Geological Circular 821, Bureau of Economic Geology, University of Texas at Austin.

Fairhead, JD., 2007. Gravity and magnetics in today's oil and mineral industry. GETECH group Plc. Kitson house. Elmete Hall Roundhay, Leeds. LS821J UK.

Fitton, JG., 1980. The Benue trough and Cameroon Line a migrating rift system. Earth \& Planetary Science Letters 51: 132-138. Elsevier Science Publishing Company.

Grauch V.J.S, Paul W. B and Keith I. K., 2004. Preliminary interpretation of high resolution aeromagnetic data near Taos New Mexico. New Mexico geological society guide book, 55th field conference, geology of the Taos region. Pp 244256.

Hogg, S., 2004. GT Gradient tensor gridding geologic structures and examples. www. Shape geophysics.com.

Isiorho, S. A., 1984. Radar geology of the Shelleng Numan area in Nigeria. An evaluation. International Journal of Remote Sensing 5(3): 519-531. 
Jain S., 1988. Total magnetic field reduction-the pole or equator? A model study. Canadian Journal of exploration geophysics. Vol. 24 No. 2. Pp. 185192.

Keary P. and Brooks M and Hill I., 2002. An introduction to geophysical prospecting, 3rd edition Pp.167172.

Kivior I. and Boyd D., 1998. Interpretation of the aeromagnetic experimental survey in Euromanga/cooper basin. Journal of Canadian exploration Geophysics V.34 Pp 58-66.

Kogbe, C. A., 1989. Paleogeographic history of Nigeria from Albian times. Geology of Nigeria. Rock view Nigeria limited Jos. 257-276.

Leu, L., 1982. Use of reduction-to-the-equator process for magnetic data interpretation: Geophysics, $47,445$.

Lu R, Mariand J. and Willen D., 2003. Differential reduction of magnetic anomalies to the equator on a massively parallel computer. Annual international meeting, society of exploration geophysics No. 69, INCONNU Vol. 68, no 6. Pp. 1945-1951.

Luo Y, Xue D. J, Wang M., 2010. Reduction to pole at the geomagnetic equator. Chinese Journal of Geophysics vol.53 No. 6 Pp. 1082-1089.

Nelson, J. B., 1998. Calculation of the magnetic gradient tensor from total field gradient measurements and its application to geophysical interpretation. Geophysics 53: 957-966.

Ofoegbu, C. O., 1985. A review of the geology of the Upper Benue Trough, Nigeria. Journal of African Earth Sciences 3: 283-291.

Ofoegbu, C. O; Morhan, N. L., 1990. Interpretation of aeromagnetic anomalies over part of south eastern Nigeria. Using a 3-D Hilbert transformation. PAGEOPH, 134(1): 13-29.
Ogunmola, J. K; Ayolabi, E. A; and Olabaniyi, S. B. 2014. Lineament extraction from spot 5 and Nigeria Sat- $X$ imagery of the upper Benue trough, Nigeria. The international archives of the photogrammetry, remote sensing and spatial information sciences, volume XL-1, 2014. ISPRS TECHNICAL COMMISSION I SYMPOSIUM, 17 - 20 November 2014, Denver, Colorado, USA. 323-330.

Oladele S., Ojo S. B. and Ako B. D., 2008. Magnetic evidence for links between basement tectonics and hydrocarbon reservoirs in the Niger delta Nigeria. NAPE extended abstract, proceedings from the 2008 NAPE conference, 11-13.

Peterson, N. R and Reeves, C. V., 1985. Application of gravity and magnetic surveys, the state of the earth in 1985. Geoph. 50: 151-172.

Phillips, J. D., 2000. Locating magnetic contacts, a comparism of the horizontal gradient, analytic signal and local wave number method. 72nd Annual International Meeting, Society of Exploration Geophysics Expanded Abstract. 402-405.

Salako K. A., 2014. Depth to basement determination using Source parameter imaging (SPI), of aeromagnetic data: an application to upper Benue trough and Borno basin, northeastern Nigeria. Academic research international. Vol.5, No. 3. Pp. 74-86.

Telford W. M., Geldart L. P., and Sherrif R. E., 1990. Applied geophysics 2nd edition. Cambridge university press - P121.

Verduco B, Fairhead J. D, Green C. M. M., 2004. New insights into magnetic derivatives for structural mapping: The leading edge V. 23 Pp 116-119.

Zaborski, P; Ugodulunwa, F; Idornigie, A; Nnabo, P; and Ibe; K., 1997. Stratigraphy and structure of the Cretaceous Gongola basin, north eastern Nigeria. Bulletin, Center Research Exploration and Production. Elf Aquitaine, 21: 153-185. 